\title{
Web-Based Literacy Information Systems as Strategies to Improve Society Reading Interest
}

\author{
Ricky Firmansyah ${ }^{1}$, Nanang Hunaifi ${ }^{2}$, Dinda Amalia ${ }^{3}$ \\ \{ricky.rym@bsi.ac.id ${ }^{1}$, masnaing@gmail.com ${ }^{2}$, dindaamalia.s326nus@yahoo.com ${ }^{3}$ \} \\ AMIK BSI Bandung, Jl. Sekolah Internasional No. 1-6 Bandung ${ }^{1,2}$, STIE Wikara, Jl. Jend. Ahmad \\ Yani No.21 Purwakarta ${ }^{3}$
}

\begin{abstract}
Indonesia's reading culture is at the lowest level when compared to ASEAN countries based on a survey released by UNESCO. The reading ability of 9-14 years children in Indonesia ranks 40th out of 40 countries studied by the Program for International Student Assessment (PISA). Efforts to improve society reading interest need to be grown since childhood. One way that the government has taken to grown children's reading interest is through the Gerakan Literasi Sekolah (GLS). However, there are no facilities that can facilitate these activities. This study is to improve society reading interest since junior high school age by facilitating their work through a webbased literacy information system. System developed with Unified Modeling Language (UML) architecture diagrams, implemented using the PHP MySQL web programming language. The results of this study are $82.91 \%$ of respondents agree this system can provides convenience and it can facilitate works and upload user's book summary.
\end{abstract}

Keywords: Internet, Information System, Literacy, Reading Interest, Website

\section{Introduction}

Indonesia's reading culture is at the lowest level when compared to ASEAN countries, with a value of 0.001 based on a survey released by the United Nations Educational Society and Cultural Organization (UNESCO). This means that only one out of a thousand Indonesian peoples has a high reading interest, even though Indonesia has enormous potential when viewed from its population. The low reading interest in a country is related to the education level [1]. The reading ability of 9-14 years children in Indonesia ranks 40th out of 40 countries studied by the Program for International Student Assessment (PISA). Efforts to improve society reading interest need to be grown since childhood so as time goes by, the natural habits of being a reader will grow [2]. Seeing these problems, Indonesia's reading interest has actually in the emergencies category, if not addressed immediately, we will be far behind other countries. Society reading interest needs to be grown from an early age in order to pursue the progress of other countries. The government and private institutions have actually made various efforts to improve society reading interest, one of which is by launching a program to read interest but the results have not been optimal [3]. One of way that the government has taken in growing children's reading interest is through the Gerakan Literasi Sekolah (GLS). GLS which is carried out collaboratively by all elements in the school and the society outside the school will indirectly drive all internal and external components of the school [4]. However, there are no facilities that can facilitate these activities. Today, the 
implementation of GLS is done by students making summaries of books they have read, then collecting them for assessment by the teacher and storing or pasting them on a literacy tree in a class that is easily damaged or lost. Making this summary is mandatory, but with the existing management there is no feedback for the summary makers or other readers.

This study is to improve society reading interest since junior high school age by facilitating their work through a web-based literacy information system. The system is designed with Unified Modeling Language (UML) architecture diagrams implemented using the PHP language and MySQL database system. This system will store reader data and book summaries that have been made for assessment. Summary of books that match the provisions will be approved by admin and displayed on the system. Registered readers can give a rating by giving a star to the reviewer who will be rated. The book summary with the most stars will be displayed on the main page of the web and the reviewer will get a reward in the form of reputation on their account so that it will be a motivation for other readers. If someone read more books, the more summaries will be made and uploaded to the web so that the chance of getting a star summary will be even greater. Indirectly, this can drive people to love reading from an early age.

\subsection{Web engineering}

Web engineering is the process of creating high quality website applications. The basic concept of web engineering adopts software engineering that emphasizes technical and management activities. Web engineering is a combination of web publishing with software engineering activities. That is because the design of a website application emphasizes more on graphic design and information design, hypertext theory and system design, and also programming. The entire system development process is carried out using multi-process process stages from the initialization of needs through analysis, design, implementation to maintenance known as the System Development Life Cycle (SDLC). Some types of models in SDLC include the Waterfall, Fountain, and Spiral models. In the waterfall model, the output from the previous step will be input for the next step [5].

While system design is the process of developing a new system based on system analysis. At the design stage, the design team is required to design the required specifications on the working paper. The working paper contains various descriptions regarding the inputs, processes, and outputs of the proposed system. The design of this literacy information system uses the waterfall method as a method for system development. In the waterfall method, each stage must be completed in full before continuing to the next stage to avoid repetition of the stages. The method of development in software (Software Development Methodology) is a guide step for the designer in developing a software. Implementing a software development method aims to make the development of an application more planned and efficient. A system development method consists of what stages must be done, what activities are there in each stage, what kind of results are expected from each stage, role of each individual and group in each activity, what tools and techniques are used.

\subsection{Literacy}

Literacy is the ability to read, write, literate or literacy which is now a term that continues to grow, so it is not strange if the type of literacy also develops [6][7]. Although there have been many types of literacy that have sprung up, but basically the essence of literacy is reading. Without reading activities, literacy of any kind will be difficult to master to the 
maximum. Thus, literacy by reading still plays a very important role. Information literacy component consists of early literacy, basic literacy, library literacy, media literacy, technology literacy, and visual literacy. In Indonesia, early literacy is needed to obtain the next stage of literacy skills. Figure 1 showing the research flow.

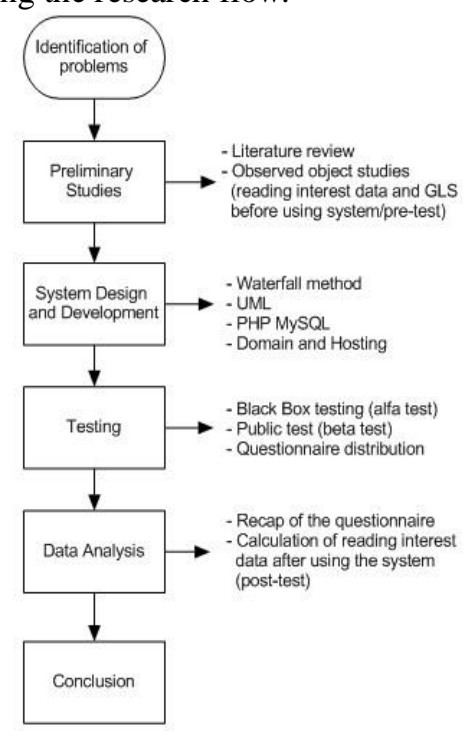

Fig. 1. Research flow.

\section{Method}

This research uses the waterfall method as a system development method. The waterfall method requires first completing each stage before proceeding to the next stage in order to avoid repeated stages. The following are the steps involved in designing a web-based literacy information system:Problems and needs analysis stages is carried out to find out and analyze the needs that will later be handled by the literacy information system. Starting from what will be the input and output, how the process is and to find out the characteristics of prospective users.

1. The design is done so that the analysis results can be implemented using a predetermined programming language.

2. Implementation and testing is the process of developing software using a predetermined programming language and ending with system testing to ensure that the system meets the expectations and is ready for use.

3. Maintenance is done in conjunction with use because bugs are often found precisely when the system has been used, therefore, regular maintenance is needed to resolve the issue.

Data collection techniques are the most strategic step in a study, considering the main purpose of the research itself is to get data [8]. Some data collection techniques used in this study are:

1. Meeting with the junior high school (Sekolah Menengah Pertama, SMP) Bahasa Teacher Subject Meeting (Musyawarah Guru Mata Pelajaran Bahasa Indonesia, 
MGMP) in First Cluster West Bandung Districts (Gugus 1 Kabupaten Bandung Barat) to exchange information and ideas through questions and answers, so as to strengthen the goals and solutions in a research topic

2. Observation technique is a direct observation of the reading interest to the early society in advance about junior high school students in connection with the literacy movement in the school and its making process, reading books that are read in the current GLS.

\section{Results}

\subsection{Use case diagram}

Figure 2 showing the literacy information. There are 4 actors in this system; admin, admin sekolah, guru and siswa. Admin has access rights to manage information systems in full, starting from managing news, announcements, managing users and so on. Siswa actors have access rights to edit profiles, create works and provide assessments on the work of other users. Guru actor has the right of access to verify students who register, edit profiles, make works and provide an assessment of the work of other users. Admin Sekolah actors have access rights to verify students or teachers who register, edit profiles, manage users, create works and provide assessments of the work of other users.

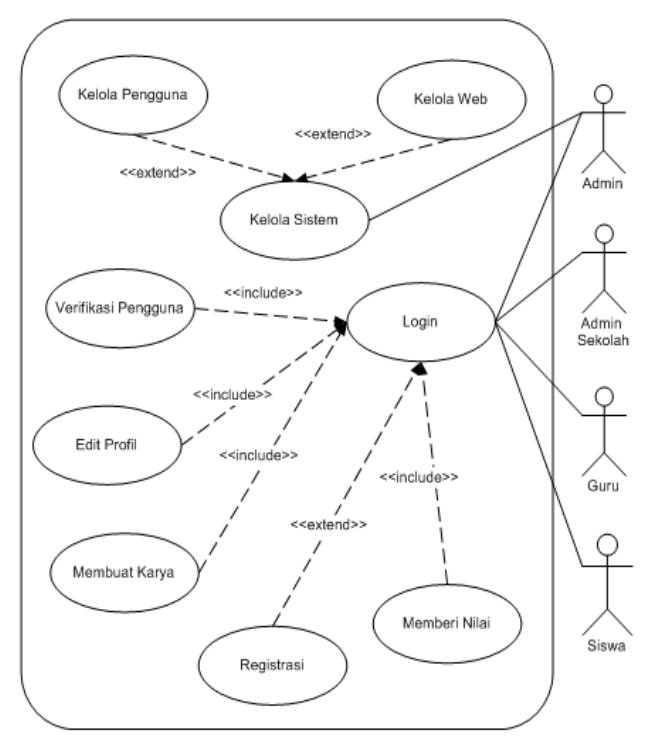

Fig. 2. Literacy information system's use case.

\subsection{System implementation.}


Each user is required to have a registered account to use this system. New account registration is done by filling out personal data on the registration page and can only be used after verified by admin. By default, the registration page that is displayed for students, shown in Figure 3. For teachers who will register, can click the teacher registration link on this registration page.

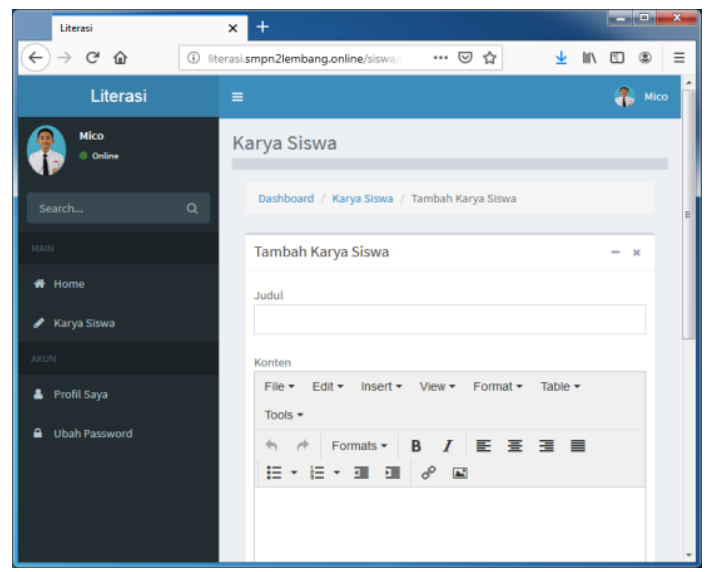

Fig. 3. Student's work page.

After the account is verified, the account can be used to create works or upload the book summary that have been made previously, this is shown in Figure 4. Every work created and uploaded on this page, will not automatically appear on the main page because it must be approved by the school admin, in this case the school admin is the teacher appointed by the school. This student work page will display a list of works that they has made including its status whether published or pending. In addition, students can delete or change the work they have made.

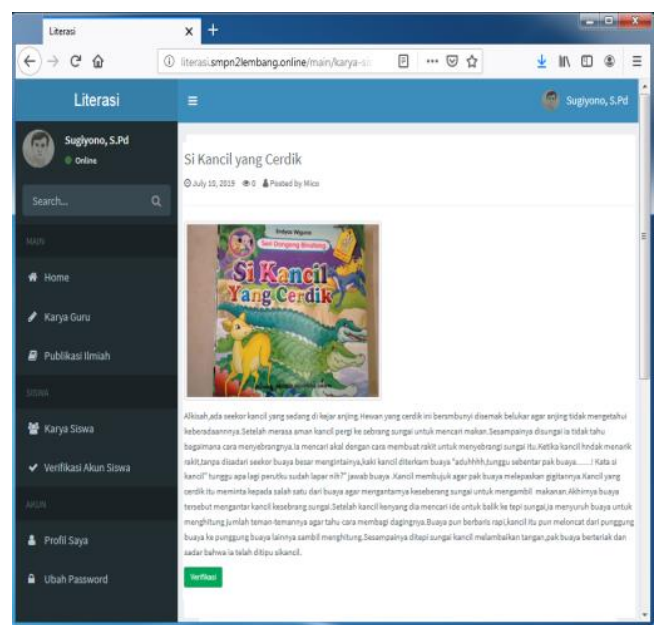

Fig. 4. Verification page to approve student's work.

The school admin page will displaying a list of works that have been made by students, here the school admin can view, check, verify (approve), reject (reject) or delete the work. 
School admins can also create works and book summary as done by students and do not require approval to display them on the main page. Figure $\mathbf{5}$ showing user rating page.

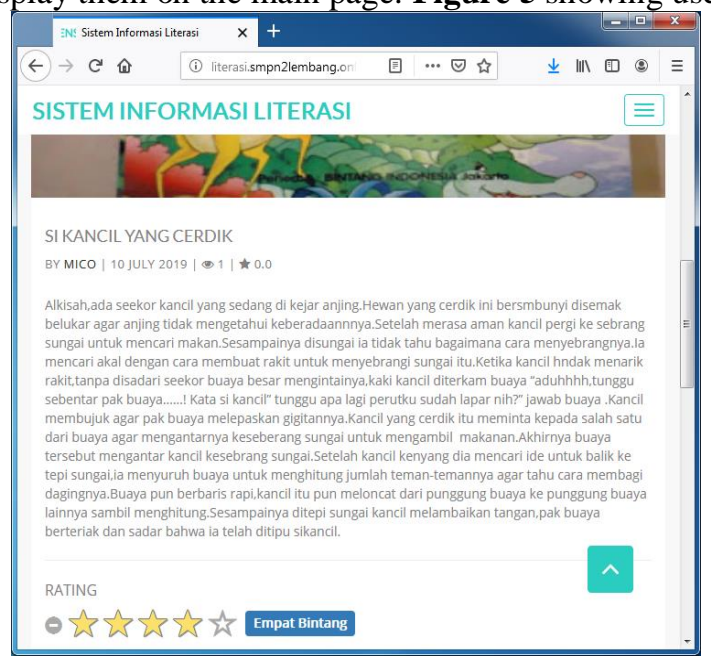

Fig. 5. User's work rating.

After the student's work is verified by the admin, it will appear on the main page and can be seen by site visitors. This work can be rated by clicking the star icon ranging from one to five stars. Only users who have been logged in and verified can give this rating. The more users create published works and the more stars they get will have a good reputation and be displayed on the main page at the best reviewer list. The black box testing result is shown in Table 1.

Table 1. Black box testing.

\begin{tabular}{lll}
\hline \multicolumn{1}{c}{ Function } & \multicolumn{1}{c}{$\begin{array}{c}\text { Results } \\
\text { Expected }\end{array}$} & Status \\
\hline Menu & Displays the main menu & Succeed \\
Beranda & Displays the main page & Succeed \\
Login/Register & Displays the login / registration page & Succeed \\
Make an article & Displays the article creating page & Succeed \\
Give a rating & Rating articles & Succeed \\
Approve article & Article publication & Succeed \\
Approve account & Activate account & Succeed \\
\hline
\end{tabular}

\subsection{Public test questionnaire.}

Questionnaires were given to users as respondents to test the level of system acceptance by utilizing Google Forms. The following is a list of questions given to 100 respondents consisting of Teachers and Students.

1. The literacy information system user interface is interesting

2. This literacy information system user interface is easy to understand

3. The literacy systems information is easy to use 
4. Information displayed on the literacy information system is useful

5. This literacy information system can help facilitate the creation of works/book summary

6. Literacy information systems provide fast responses

7. The menus and navigation on the literacy information system are easy to understand

8. I feel satisfied using this literacy information system

9. I want to have this literacy information system

10. I would recommend this literacy information system to relations or friends

The table below presents the results of the questionnaire calculation using the percentage calculation within Equation 1, and the result can be seen in Table 2.

$$
\text { Percentage Results }(\%)=(\mathrm{NRR} / \mathrm{NR}) \times 100 \%
$$

Information :

NRR = Number of Respondent Ratings

NR $\quad=$ Number of Respondent

The results of the questionnaire show 100 respondents gave a positive response of $82.91 \%$ for this system. It can be concluded that this web-based literacy information system can help users to create works and upload book summary easily. The documentation can be seen in Figure 6.

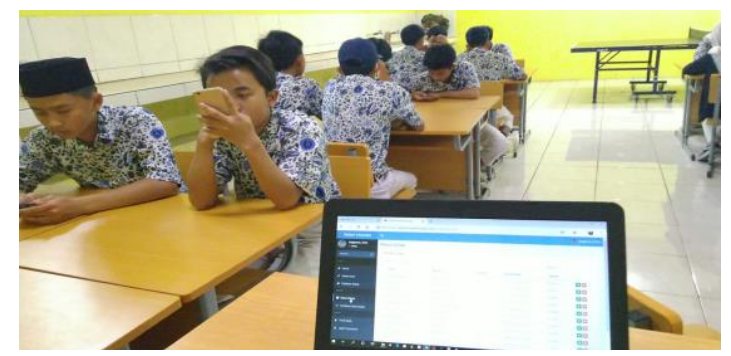

Fig. 6. Literacy information system is testing in SMP Negeri 2 Lembang, West Bandung districts.

Pre-test data were taken in May 2019 from the number of participation in the making of book summary by Class IX students at SMP Negeri 2 Lembang, West Bandung Districts in 2018/2019 School Year who had not used the system totaling 72 students. Post-test data were taken in August 2019 from the number of participation in book summary by class IX students in the 2019/2020 School Year using who a literacy information system totaling 209 students. Moreover, there has been an increase in the level of student participation that makes a book summary with a gap of 137 students, it means there has been an increase in student's reading interest.

\section{Conclusion}

Based on this research, below is some conclusions:

1. Reading interest in Indonesia has been in the emergency category, society reading interest needs to be grow from an early age in order to pursue the progress of other 
countries. The reading ability of children aged 9-14 years in Indonesia ranks 40th out of 40 countries studied by the Program for International Student Assessment (PISA). One of way that the government has taken in growing children's reading interest is through the Gerakan Literasi Sekolah (GLS) but not optimal, there are no facilities that can facilitate these activities.

2. The web-based Literacy Information System has been designed using UML architecture diagrams which are implemented using the PHP web programming language and the MySQL database system. This system will store reader data and book summaries that have been made for assessment. Summary of books that match the provisions will be approved by admin and displayed on the system. Registered readers can give a rating by giving a star to the reviewer who will be rated.

3. The results of the questionnaire calculation show 100 respondents gave a positive response of $82.91 \%$ for this system. It means that this web-based literacy information system can help users to create works and upload book summary easily.

Acknowledgment. Thanks to the Directorate General of Strengthening Research and Development of the Ministry of Research, Technology and Higher Education of the Republic of Indonesia for funding so that this research can be carried out.

\section{References}

[1] Benny, G., \& Abdullah, K.: Indonesian perceptions and attitudes toward the ASEAN Community. Journal of Current Southeast Asian Affairs, 30(1), 39-67 (2011)

[2] Maccoby, E. E.:The role of parents in the socialization of children: An historical overview (1994)

[3] Snow, C. E., \& Biancarosa, G.: Adolescent literacy and the achievement gap: What do we know and where do we go from here? New York: Carnegie Corporation of New York (2003)

[4] Aiga, R.: SekolahDasar.Net.http://www.sekolahdasar.net/2016/09/gerakan-literasi-sekolahgls.html (2016)

[5] Petersen, K., Wohlin, C., \& Baca, D.: The waterfall model in large-scale development. In International Conference on Product-Focused Software Process Improvement (pp. 386-400). Springer, Berlin, Heidelberg (2009)

[6] Paul, P. V.: Literacy and deafness: The development of reading, writing, and literate thought. Boston: Allyn and Bacon (1998)

[7] Opoku-Amankwa, K., \& Brew-Hammond, A.: 'Literacy is the ability to read and write English': defining and developing literacy in basic schools in Ghana. International journal of bilingual education and bilingualism, 14(1), 89-106 (2011)

[8] Lethbridge, T. C., Sim, S. E., \& Singer, J.: Studying software engineers: Data collection techniques for software field studies. Empirical software engineering, 10(3), 311-341 (2005) 